\title{
Cognitive mapping links human factors to corporate strategies
}

\author{
Judy Village*, Filippo A. Salustri and \\ W.P. Neumann
}

Human Factors Engineering Lab,

Department of Mechanical and Industrial Engineering,

Ryerson University,

350 Victoria St., Toronto, Ontario, M5B 2K3, Canada

Fax: 604-929-7280

Email: jvillage@ryerson.ca

Email: salustri@ryerson.ca

Email: pneumann@ryerson.ca

*Corresponding author

\begin{abstract}
Human factors (HF) can improve business performance. Our objective is to harness individual tacit knowledge from senior directors about human factors as it relates to strategic goals and to make explicit their shared managerial thinking with an aim to identifying improvement opportunities using HF. Individual cognitive maps were drawn during one-hour interviews with seven senior directors of a large electronics firm. The maps were then merged on a common strategic goal of 'improving quality' into a group map containing 221 concepts and 900 loops. In a two hour workshop with the directors, reducing fatigue, improving systems design, and reducing repetitive activities were concepts that emerged as critical-to-quality. Workshop discussions identified untapped improvement opportunities. Directors viewed the maps as a dynamic indicator of their HF performance. Making the connection between HF and strategic goals explicit can help an organisation identify opportunities to improve human, and therefore business, performance. [Received 4 April 2013; Revised 12 June 2013; Revised 20 June 2013; Accepted 9 July 2013]
\end{abstract}

Keywords: macroergonomics; participatory ergonomics; tacit knowledge; manufacturing; business improvement.

Reference to this paper should be made as follows: Village, J., Salustri, F.A. and Neumann, W.P. (2016) 'Cognitive mapping links human factors to corporate strategies', European J. Industrial Engineering, Vol. 10, No. 1, pp.1-20.

Biographical notes: Judy Village is a Certified Professional Ergonomist in the USA and Canada. She is an Adjunct Professor in the School of Population and Public Health at University of British Columbia, where she teaches a masters course in Ergonomics. She has conducted applied research for 25 years in areas of musculoskeletal disorders, whole body vibration and ergonomics regulations. She completed her $\mathrm{PhD}$ in Industrial and Mechanical Engineering at Ryerson University. Her research explores the facilitators and barriers of integrating human factors into the design process of organisations. 
Filippo A. Salustri has been teaching, researching, and practising design engineering since 1989. He has been involved with research and design of cars, aircraft, spacecraft, robots, temporary structures, toys, home appliances, and medical equipment. His research interests include formal and informal methods of designing, information visualisation, and web-based design tools. $\mathrm{He}$ is a member of the Design Society, the Design Research Society, CSME, IEEE, and INCOSE; he is a founding member of the Canadian Engineering Education Association. He is currently an Associate Professor of Mechanical Engineering at Ryerson University.

W.P. Neumann holds a Doctorate in Design Science from Lund University, Sweden, and is a certified European Ergonomist. He is currently an Associate Professor in the Mechanical and Industrial Engineering Department at Ryerson University where he directs the Human Factors Engineering Lab. His research interests include the strategic advantages of human factors, organisational design and management, and change management for the application of human factors in design processes. His research work focuses on the contact point between organisational management theory and human factors application practice in industry with the aim of helping produce high performing work systems that are sustainably competitive.

This paper is a revised and expanded version of a paper entitled 'Linking human factors to corporate strategy with cognitive mapping techniques' presented at the International Ergonomics Association Conference in Recife, Brazil, 12-16 February 2012.

\section{Introduction}

This paper presents results of a cognitive mapping exercise carried out with seven senior directors of a large electronics manufacturer. The goals were

a to harness individual tacit knowledge from senior directors about human factors as it relates to strategic goals

b to make explicit their shared managerial thinking with an aim to identifying improvement opportunities using HF.

This paper will discuss how seven individual maps were merged into a group map aligned to the most important identified strategic goal of 'improved quality', and how this led to identification of HF opportunities. The authors conclude that cognitive mapping may be a useful technique for a learning organisation to identify ways of capitalising on their tacit knowledge about human factors to improve human performance, and therefore business success.

In this first section, we discuss the background and justification for making explicit the HF knowledge of senior directors, and linking that knowledge to strategic goals. The case study setting is also described. In the second section, we explain the cognitive mapping data collection and analysis. The third section presents results of qualitatively coded themes from the individual maps, as well as quantitative calculations of the most central concepts from both individual and the merged group map. Two smaller maps are shown of the most central concepts from the group map. The third section also includes the outcome of the workshop discussion and evaluations. The fourth section provides an 
interpretation of the mapping results, and discusses methodological and application issues.

\subsection{Background and justification}

Human performance is critical to the success of operations, but frequently the human performance aspects of work are divorced from the operational management aspects (Boudreau et al., 2003; Neumann and Dul, 2010). Lack of consideration for the social or human system is the main reason the Harvard Business Review quoted only $15 \%$ of reengineering efforts (such as zero-defects or lean manufacturing) as being successful (Wilson-Donnelly, 2005). There are many examples where HF considerations provided value added to operations management, as discussed by Boudreau (2003), and shown in case studies of production jobs (Womack et al., 2009), and among road maintenance workers (Ryan et al., 2011). There are also many examples in the HF literature showing improvements in business performance, such as increased productivity, improved customer service, reduced errors, and reduced quality defects (Drury, 2000; Eklund, 1995, 1997; Neumann and Dul, 2010). Despite the evidence, consideration of HF is often underutilised in manufacturing organisations (Helander, 1999).

One reason for this underutilisation may stem from the lack of attention given to HF by senior management since the contribution of HF to business strategies and their implementation is not understood (Dul and Neumann, 2009; Drury, 2000). The authors believe senior management have implicit knowledge about the importance of HF, but unless tacit knowledge is shared and made explicit, it cannot be put into action (Siemieniuch and Sinclair, 2004). Successful organisations are said to have a shared vision upon which everyone agrees (Senge, 2006). They also can translate tacit knowledge (information, skills, attitudes, experiences and judgements) into practice, and become 'learning organisations' (Mohanty and Deshmukh, 1999). Companies that have enduring success create learning organisations where members can adapt strategies and practices to a dynamic world (Mohanty and Deshmukh, 1999). The authors believe HF can enhance business performance in a learning organisation, but the first step within the organisation is to articulate a priori knowledge. We will demonstrate that cognitive mapping, a tool from the operations research and management fields, can translate tacit knowledge into practice (Village et al., 2013). By reframing corporate strategies to include $\mathrm{HF}$ and cut across organisational boundaries, new routines for action that include HF can be implemented (Neumann and Village, 2012; Tranfield and Smith, 1998).

The goals of this case study paper are to illustrate how cognitive mapping can make tacit knowledge of HF from individual senior directors explicit to themselves and each other and to reveal the relationship between HF and the organisations' strategic goals, as well as lead to improvement actions.

\subsection{Case study setting and the larger research collaboration}

The cognitive mapping exercise discussed in this paper is part of a multi-year research collaboration between the Human Factors Engineering Lab at Ryerson University's Department of Mechanical and Industrial Engineering, and a large electronics manufacturing company in Canada. The goal of the collaboration is to improve the organisations' capabilities to apply human factors in the design of their production 
systems (assembly lines, tools, equipment, design processes) to improve both human and system performance.

A single longitudinal case study approach was used since the organisation provides a unique and rarely accessible opportunity to integrate HF into their design processes, and monitor the development over time (Yin, 2009). Researchers were interested in conducting a cognitive mapping exercise approximately two years into the collaboration for the following reasons:

- a new steering committee of senior directors had just been convened to provide enhanced direction for the collaboration

- the senior directors spanned several different departments

- the senior directors had recently re-defined their organisations' strategic goals

- up to that point, the HF specialists within the organisation had had little involvement in the production systems design process or knowledge of strategic goals.

The steering committee was supportive of the cognitive mapping exercise as a means to make HF knowledge explicit and reveal connections with the new organisational strategy. It was also intended that the merged group map would provide actionable options to further the HF goals of the ongoing research and development collaboration in ways that support core organisational needs.

\section{Methods}

A cognitive map is a graphical representation of the content and structure of an individual's belief system (Eden et al., 1992). Cognitive mapping has been used to address complex problems, formulate strategies, facilitate decision-making and negotiation, for organisational learning, to develop shared mental models, and to capture individual and organisational cognition (Howick et al., 2008; Tegarden and Sheetz, 2003; Lee et al., 1992; Moreroft, 1992). To our knowledge, it has not been used in the HF domain. A detailed methodological review and demonstration of a single case study using cognitive mapping to elicit HF knowledge can be found in Village et al. $(2012,2013)$.

\subsection{Data collection for individual maps}

A one-hour interview was conducted and digitally recorded with each of seven senior directors representing manufacturing engineering, advanced engineering, continuous improvement and Ergonomics. The open-ended question posed to each director was: "How can integrating human factors into your production system design processes help you achieve your strategic goals?" As directors responded to the question, a map with action-oriented concepts in the directors' own words was hand drawn and linked with directional (causal) arrows on an oversized sheet of paper. Strategic goals were placed at the top of the paper, sub-goals in the middle, and actions to achieve goals at the bottom (see Eden and Ackermann, 2004). 
The digital recording was later reviewed to verify accuracy of wording of each concept and direction of each link. Concepts and links were entered into Decision Explore software (Banxia Software Ltd. 2002, U. of Strathclyde) and linkages were disentangled as much as possible to facilitate comprehension of the map.

\subsection{Data analysis and development of the merged group map}

\subsubsection{Individual map: qualitative analysis}

Concepts on the individual maps were coded by dominant themes (Strauss and Corbin, 1990) as they emerged in analysis (by assigning unique box structures to each concept). The number of concepts within each of the themes was counted, clustered, and compared between directors. The most common strategic goal mentioned by the directors was chosen as the key to merge the individual maps into a single group map.

\subsubsection{Development of the merged group map}

Starting with the most complex individual map, a second individual map was merged on the common goal using the Decision Explore software. The software combines concepts and links from both maps on the common goal. This merging process was repeated until all of the seven individual maps were combined into a single merged map. Concepts were carefully reviewed for duplicate concepts, in which case the duplicates and all related links were combined. Concepts on an individual map that did not link to the common goal were considered 'orphaned' and were eliminated from the final merged map. The removal of duplicated and orphaned concepts and links means the merged map contains fewer concepts than the sum of each person's individual map. The final merged map was then re-drawn to untangle concepts as much as possible.

\subsubsection{Quantitative analysis: individual and merged group map}

Data from both the individual and merged group maps were analysed for descriptive statistics using the Banxia Software, including: the total number of concepts; number of heads (concepts at the top of the map with multiple concepts leading into them); number of tails (action items at bottom of map); and number of loops. Data from individual and merged maps were also analysed for 'centrality' of each concept. Centrality analysis is performed by assigning a value of 1.0 to each direct link, and a diminishing weight (distance decay function) for each link removed from the central concept (such as 0.7, $0.5,0.3$, etc). Concepts with the highest centrality scores reflect those with the highest overall density of network linkages. Smaller maps were then drawn based on concepts with highest centrality scores from the merged group map (c.f. Village et al., 2013).

\subsection{Workshop method to review merged group map and determine action}

\subsubsection{Workshop approach}

A workshop was held with the team of directors to review the combined map and identify HF action opportunities. Prior to the workshop, each director was provided with an electronic version of their own individual maps, and drawings of three of their smaller maps based on their most central concepts. At the two-hour workshop, directors were 
provided with a package of their individual maps, which were treated as confidential, as well as results of the merged group map (descriptive statistics and smaller maps). Findings from the merged group map were presented and discussed at the workshop. Directors were encouraged to discuss observations from the maps and themes presented. The workshop ended with a brainstorming of potential action items arising from the merged group map.

\subsubsection{Data collection in the workshop}

The workshop was digitally recorded, transcribed, and entered into NVivo software (QSR International, 2010). Notes were also recorded during the meeting by the facilitator and three other Ryerson researchers. The notes and the transcription were reviewed using a general inductive approach for discussion points, decisions, and themes. Quotes from the workshop were collected to highlight the findings.

\subsubsection{Workshop and mapping evaluation survey}

At completion of the workshop, the directors completed a written evaluation and rated (on a seven-point Likert type scale) the usefulness of the maps (individual, group and smaller maps), as well as the workshop. Directors were also asked whether they would recommend others use the mapping tool, and how interested they were in performing the mapping exercise in the future to compare findings. Finally, participants completed open-ended questions about what they gained from the workshop and any further suggestions.

Data from the evaluations were entered into excel software and mean ratings and standard deviations were calculated. Themes emerging from the open-ended questions were summarised.

\section{Results}

In this section, the qualitative themes from each of seven individual maps are compared and contrasted. The quantitative descriptive statistics of the seven individuals, as well as the merged group map are then presented, with some basic interpretation of the findings related to map size and structure. Concepts with the highest centrality scores are listed, and smaller maps are presented for two of these central concepts. Finally, the results of the workshop and workshop evaluations are presented.

\subsection{Qualitative themes from individual maps}

In linking HF to strategic goals, seven common themes emerged from qualitative coding of the directors' concepts in the individual maps. Figure 1 shows the distribution of themes (by number of concepts per theme) for each director, and the average for the group. Definitions for each theme are provided below:

- quality: pertaining to detection or elimination of errors or defects

- process rigor: pertaining to standards, processes and technologies to ensure adherence to performance goals 
- design of process: pertaining to design of manufacturing, assembly, tooling and materials used in assembly

- product design: pertaining to design of the product, feedback to product designers or satisfaction of designer needs

- cleanliness: pertaining to procedures, processes and the experience of ensuring minimal contamination of the product during manufacturing and assembly

- psychosocial factors: pertaining to the perceptions of workers concerning how the work is structured and carried out (such as stress, motivation, engagement and involvement)

- client/partner service: pertaining to the ability to satisfy customers or partners requirements (manufacturing or supply).

The theme most discussed when asked to consider HF with respect to strategic goals was process design (33.3\% of concepts, range $23-46 \%$ ). This theme included improvements to design and layout of equipment, tools, and fixtures as an important way to achieve the strategic goals. Concepts relating to quality represented on average $18 \%$ of concepts (range 1-31\%), and a further $11.4 \%$ related to process rigor (range $0-17 \%$ ). HF concepts related to quality include, for example, 'improve ability to detect failure/bad components', 'ensure all equipment is right', and 'group like actions together'.

Figure 1 Distribution of percent of concepts associated with each theme for each of the seven directors (1-7) and the average (8) of all directors

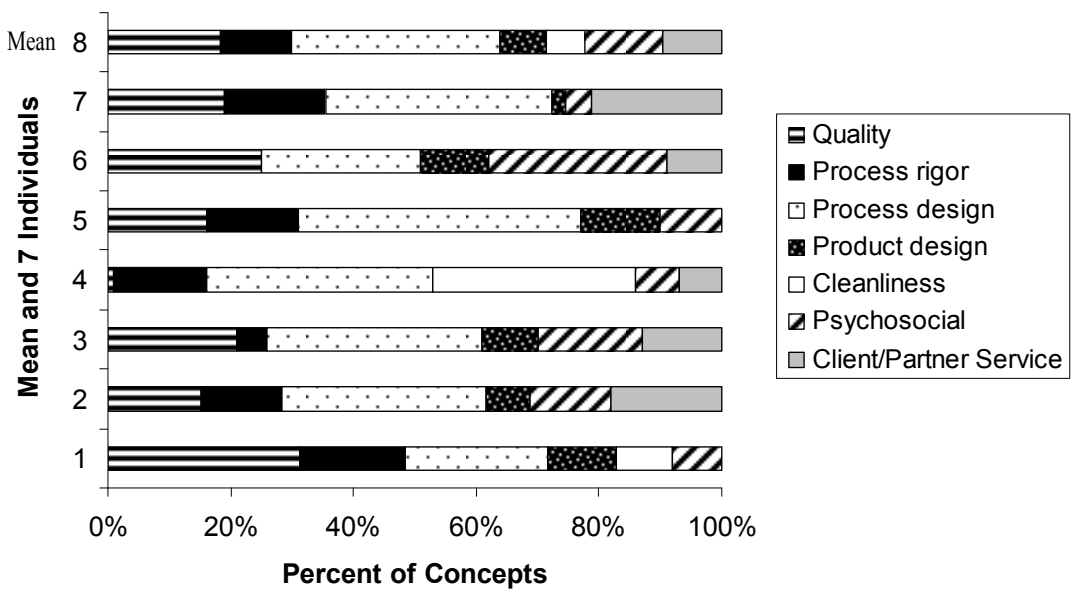

Considerable variability was found between directors. Psychosocial factors, for example, represented $29 \%$ of concepts for one director (of the ergonomics group), but as little as $4 \%$ for some other directors. Psychosocially-related factors included improving worker buy-in, recognition from leaders, increasing pride, and improving relations between workers and supervisors. The extent of discussion regarding cleanliness $(6 \%$ of concepts on average), product design (7.6\%) and client/partner service (9.4\%) varied depending on the role of the particular director. Some directors stated they have little influence on product design, so they did not discuss it. Other directors suggested improved product design was highly central to improving production design, and therefore quality. 


\subsection{Quantitative analysis of maps}

\subsubsection{Descriptive statistics of individual maps}

Table 1 shows the descriptive statistics for each individual map, as well as for the merged group map. The total number of concepts derived in one hour ranged from 69 to 91 . The number of tails was consistently higher than the number of heads, suggesting a relatively flat (as opposed to steeply hierarchical) shape of each person's map. This in combination with a high ratio of tails to concepts illustrates a large range of possible intervention options, as understood by these directors, for achieving their company's goals. The number of loops varied dramatically, from 0 for one director, to 900 for another. Higher numbers of loops, depending on the individual and context, can illustrate greater understanding of a topic. Loops can also illustrate the possible existence of dynamic considerations within an issue (i.e. exponential growth or decline), and may be an indication of the complexity of the issue (Eden and Ackermann, 2004). They should be interpreted with care and consideration of the context. The number of main strategic goals identified by each senior director ranged from 1 to 4 , and sub-goals ranged from 2 to 7 .

Table 1 Summary of descriptive statistics for each individual map and the merged map

\begin{tabular}{|c|c|c|c|c|c|c|c|c|c|}
\hline \multirow{2}{*}{ Descriptive statistic } & \multicolumn{8}{|c|}{ Individual maps } & \multirow{2}{*}{$\begin{array}{c}\text { Merged } \\
\text { map }\end{array}$} \\
\hline & 1 & 2 & 3 & 4 & 5 & 6 & 7 & Mean (SD) & \\
\hline Number of concepts & 69 & 65 & 86 & 84 & 75 & 74 & 91 & $77.7(9.5)$ & 221 \\
\hline Number of heads & 12 & 15 & 18 & 4 & 18 & 8 & 14 & $12.7(5.2)$ & 43 \\
\hline Number of tails & 14 & 23 & 29 & 45 & 28 & 26 & 36 & $28.7(9.8)$ & 77 \\
\hline Heads: concepts & 0.17 & 0.23 & 0.21 & 0.05 & 0.24 & 0.11 & 0.15 & $0.2(0.1)$ & 0.19 \\
\hline Tails: concepts & 0.20 & 0.35 & 0.34 & 0.54 & 0.37 & 0.35 & 0.4 & $0.4(0.1)$ & 0.35 \\
\hline Number of loops & 0 & 1 & 137 & 37 & 900 & 2 & 384 & $208.7(334.8)$ & 900 \\
\hline Number of goals & 1 & 3 & 2 & 2 & 2 & 1 & 4 & $2.1(1.1)$ & 3 \\
\hline Number of sub-goals & 3 & 2 & 3 & 4 & 6 & 7 & 3 & $4.0(1.8)$ & 8 \\
\hline
\end{tabular}

The strategic goal 'improve quality' was the most common and therefore the concept chosen for merging the seven maps. Other goals listed by at least three managers included: 'increase productivity and throughput'; 'improve product design'; and 'improve position as a manufacturing centre that focuses on new product realisation'.

\subsubsection{Merged group map}

The merged group map based on the common concept 'improve quality' resulted in a total of 221 concepts. It is shown in Figure 2, not for the purpose of reading the text boxes, but instead to illustrate the complexity and high interconnectedness of concepts. Strategic goals can be identified by large circles and sub-goals by square boxes. Since the merging establishes all links to a concept from each individual, a large number of loops and tails were maintained in the final map. The 77 tails represent different human factors-related actions that can lead, by various routes, to the strategic goal of improved quality (for example, improve design of equipment). The ratio of links to concepts in the merged map is 1.55 , well above typical ratios (1.15 to 1.2$)$ even for persons with 'expert' knowledge about a topic (Eden et al., 1992). 
Figure 2 Merged map from goal 'improve quality' based on seven individual maps (for illustration purposes, not for reading)

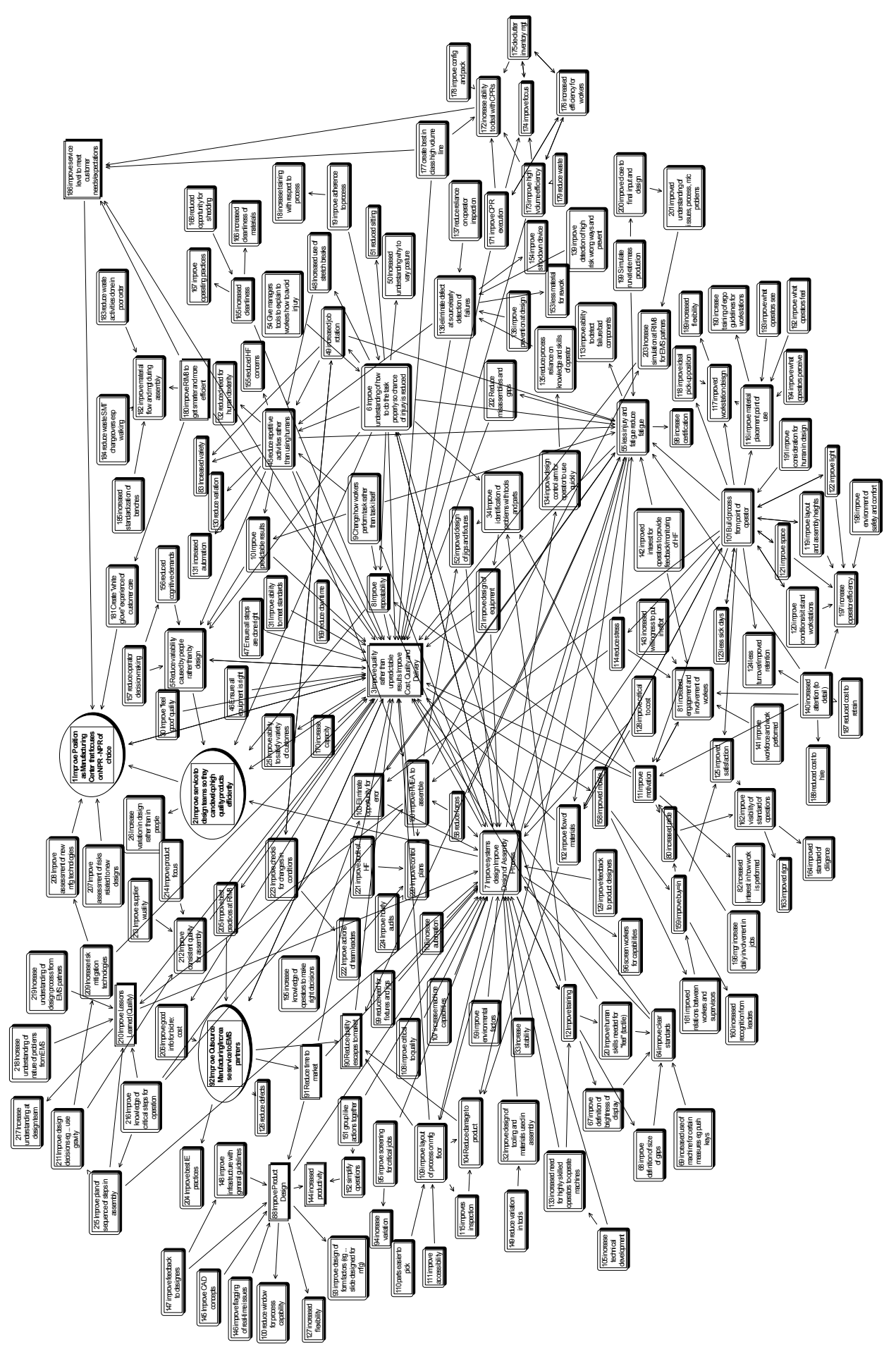




\subsubsection{Most central concepts}

The centrality scores and number of concepts linked to the most central fifteen concepts of the merged group map are shown in Table 2. Not surprisingly, the strategic goal of improved quality is the most central concept by nature of the merging of individual maps.

Table 2 Top 15 most central concepts from the map merged on quality (centrality score and number of concepts linked)

\begin{tabular}{lcc}
\hline Merged map on quality: central concepts & Centrality score & \# concepts linked \\
\hline Increase quality & 110 & 198 \\
Improve systems design & 100 & 191 \\
Reduce fatigue & 91 & 186 \\
Increase understanding of how to do the task & 87 & 186 \\
Improve service to design teams & 83 & 188 \\
Reduce repetitive activities & 78 & 166 \\
Increase motivation & 77 & 178 \\
Improve repeatability & 77 & 184 \\
Improve layout of process on manufacturing floor & 75 & 175 \\
Build process from point of view of operator & 74 & 160 \\
Improve lessons learned (quality) & 71 & 169 \\
Improve flow of materials & 70 & 168 \\
Reduce time to market & 70 & 169 \\
Improve clear standards & 70 & 169 \\
Improve design of equipment & 68 & 170 \\
\hline
\end{tabular}

Of the 15 central concepts listed in Table 2, almost all of the concepts have HF aspects. For example: 'reduce repetitive activities', 'increase understanding of how to do the task', 'build the process from the point of view of the operator', 'improve design of equipment' and 'improve flow of materials'. The third most central concept was 'reduce fatigue'. When reviewing the top five central concepts of each individual, two directors had 'reduce fatigue' as a central concept. However, when the concepts were merged, 'reduce fatigue' emerged as a highly central concept strongly linked to improving quality. Similarly, 'improve understanding of how to do the task' was a central concept for only one director in the individual maps. However, when links and concepts from the group were merged with this concept, it became a central concept for the group map due to related links. Two other concepts similarly emerged as high scoring central concepts: 'reduce repetitive motions' and 'improve motivation'.

\subsubsection{Re-drawing smaller maps of most central concepts}

Two of the smaller maps, re-drawn based on the most central concepts mentioned by the directors, are shown in Figure 3 for 'reduce repetitive activities', and Figure 4 for 'reduce fatigue'. 
Figure 3 Concepts linked to central concept of 'reduce repetitive activities' from map merged on 'improve quality' from seven directors

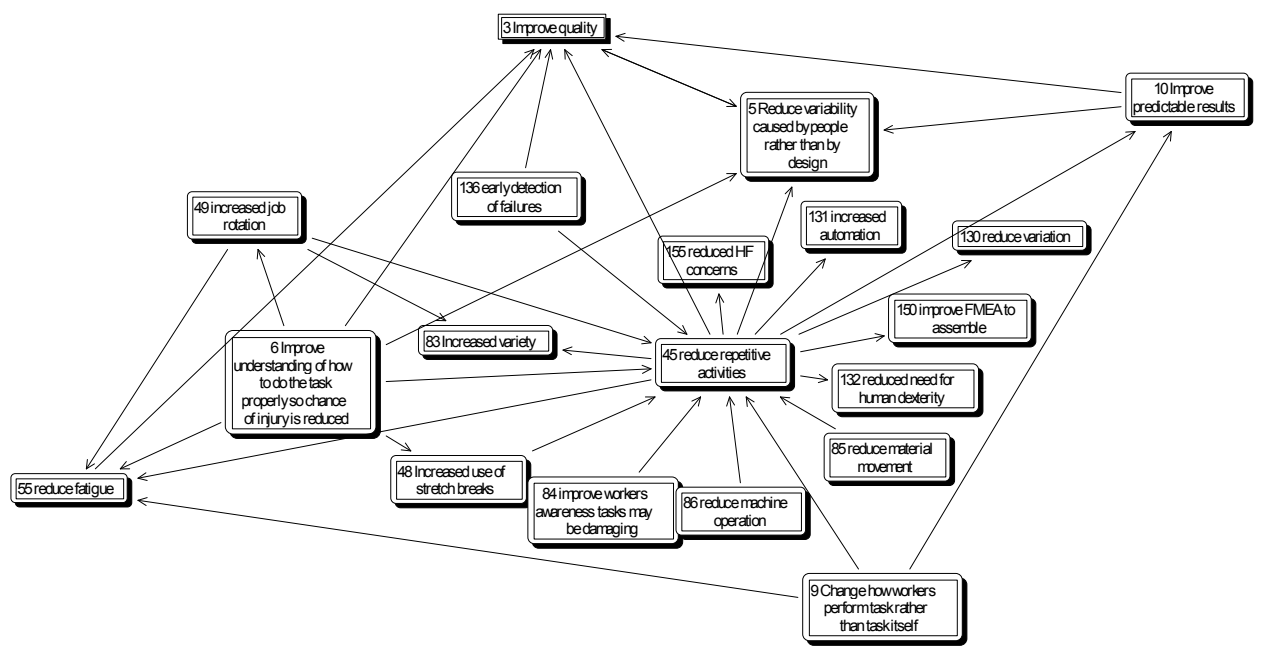

Figure 4 Concepts linked to 'reduce fatigue' from a map merged on 'improve quality' from the seven managers

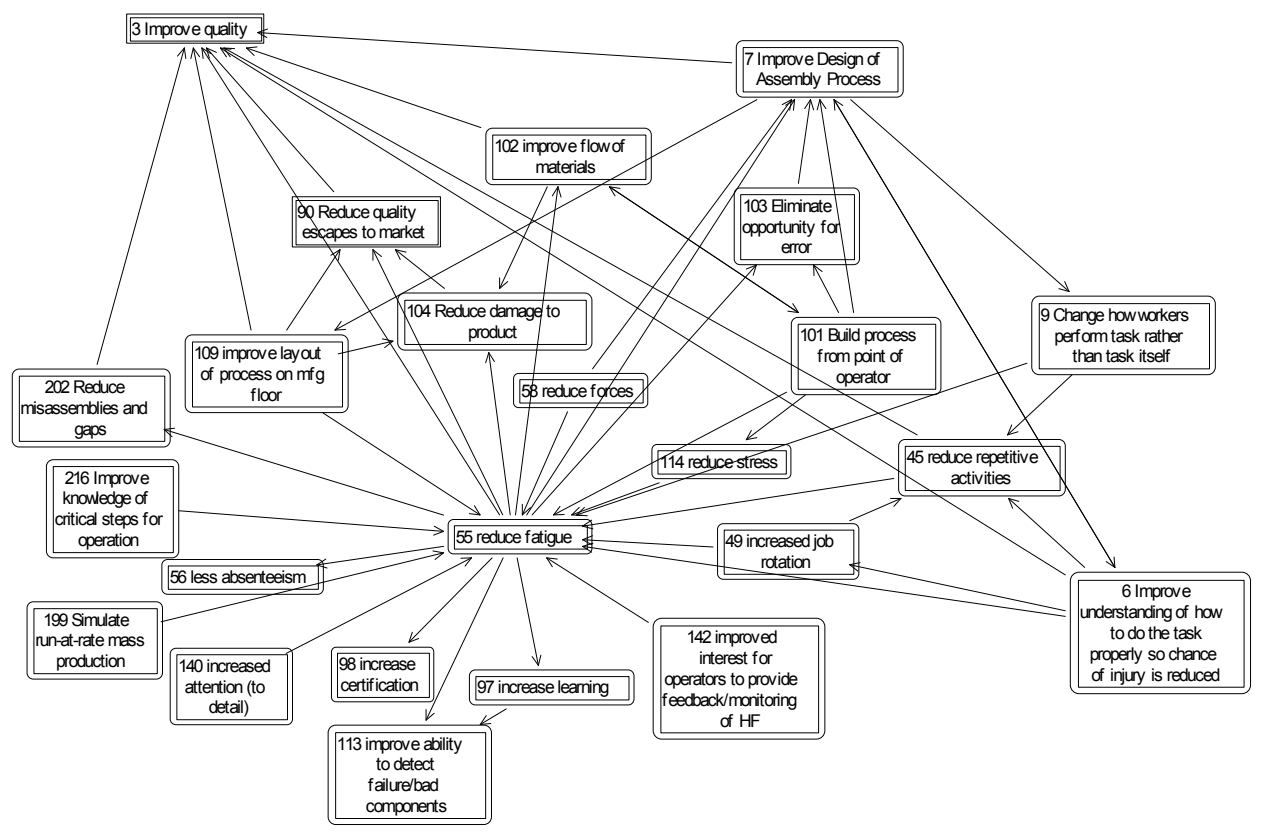

'Reduce repetitive activities' (concept box number 45), found in the middle of the map in Figure 3, has a direct link to the main goal of improved quality (\#3 at top) and a link to 'reduce fatigue' (\#55), which also links directly to improved quality. There are another ten 'consequences' (arrows leading out of box 45) of 'reducing repetitive activities', such as 'increased variety' (\#83), and 'reduced HF concerns' (\#155). The small map illustrates the intricate links between quality and human factors that were identified by the directors 
during the interviews. The eight explanations for ways to reduce repetitive activities (arrows leading into box number 45) include, for example 'reducing material movement' (\#85), and 'change how the operators perform the task rather than the task itself' (\#9). These latter concepts, or tails, are potential action items that, in the perception of the group, lead to reduced repetition, and thereby to improved quality.

Figure 4 also contains the central concept of 'reduce repetitive activities' (box \#45) on the right side showing how the small maps overlap. 'Reducing fatigue' was also directly linked to improving quality, and had numerous other indirect connections to the main goal as well. The explanations for ways to reduce fatigue are numerous as seen in Figure 4. Noteworthy for human factors considerations include for example 'improving layout of process on the manufacturing floor' (\#109), 'improving knowledge of critical steps for operation' (\#216), and 'improving interest for operators to provide feedback/monitoring of HF' (\#142). Therefore, while both central concepts discussed in Figure 3 and Figure 4 lead directly to improved quality, there are numerous other effects and routes they may take to arrive at the strategic goal.

\subsection{Workshop results}

The maps presented at the workshop led to a discussion among the directors about two main findings and two main opportunities, described below. In addition, we will describe how the managers treated the maps as valuable indicators of HF performance. Finally, we will present results of the evaluations of both the maps and the workshop.

\subsubsection{Two main findings by the participants}

There was considerable discussion when Figure 1 was presented at the workshop showing the distribution of concepts from each theme. The directors noticed that process design was the theme with the majority of concepts for each individual. There was a consensus that their process design is the single largest influence of good quality. It was stated that this 'finding' confirms the organisations' internal emphasis at the time of the workshop on improving process design. Quality, in fact, was discussed as being the by-product of good process design. One person commented that if we improve process design, then quality would follow automatically. Within this theme, there were expressions about how visual and apparent this finding was when looking at the maps. One person stated:

"it's interesting how the loops go around and it all makes sense"

And another:

"it's like an oh my gosh, if we had better design, it would impact all these things..."

The second main finding from the maps was the direct and indirect relationships between fatigue and quality that became apparent to the directors. One participant noted that fatigue and quality seem to go hand-in-hand, and that fatigue is not only the root cause of our quality problems, but one of the biggest factors. One person stated that "fatigue seems to sum it up" when referring to the number of links between quality and fatigue. The directors looked closely at the quality issues linked to fatigue. Each person could see 
their concepts, but the group map revealed new concepts from other directors. For example, one person expressed interest in how the map revealed that fatigue affects the ability to detect a quality issue. Some directors had not previously made these connections.

\subsubsection{Two main action opportunities}

In viewing the maps, the directors realised there was a need in their organisation to look holistically at broader systems design issues (for example floor flow, patterns of work, job rotation and enlargement, etc.). This realisation led to suggestions for various initiatives looking at systems design aspects. The second outcome opportunity revealed by the maps pertains to psychosocial factors. The directors were interested in the notion of improving the workers' understanding of how to do the task properly. Linked to this were concepts such as involvement, ownership, empowerment, and taking leadership with respect to quality. One director mentioned that "it is interesting to see that if we improve workers' understanding of their tasks, this will lead to improved repeatability - which is important for quality". As with the systems design gap, there were also suggestions made for initiatives that could improve psychosocial aspects of the work environment.

In total, the brainstorming session based on the two outcome opportunities led to a list of 12 potential initiatives (actions) derived directly from the merged group map and discussion during the workshop.

\subsubsection{Observations about use of the maps in the workshop}

Throughout the workshop, directors were observed to be checking their own individual maps and comparing information with the merged group map. There was a tendency among directors to assume the map was the 'correct' view of the workplace - or an indication of organisational performance with respect to HF. One director indicated "if we address some of the issues - maybe the map will change". In other words, the map indicated problems and potential solutions and would change when problems are resolved. They therefore saw the map as being dynamic and changing over time and its value as an indicator of performance.

\subsubsection{Results of the evaluation of the maps and workshop}

Overall, the mapping tool, mapping exercises and workshop were felt to be very worthwhile, enjoyable, and were highly recommended for other organisations. The mean scores on a 0-7 scale (with 0 being 'not at all' and 7 being 'extremely') ranged from 5.2 to 6.2 (standard deviations ranged from 0.4 to 1.1 ). The highest rating was whether participants were interested in repeating the mapping exercise in the future (6.2). Mean scores of 6.0 were reported for the usefulness of the smaller maps for understanding the link between HF and strategic goals and the discussion arising from the maps. In the open-ended questions, directors commented that they were surprised and intrigued at how much information (shown on the maps) came out of a one-hour interview. 


\section{Discussion}

\subsection{What cognitive mapping revealed about HF and strategic goals}

The cognitive mapping technique revealed the main strategic goals of the organisation and their links to HF. It also helped identify HF initiatives that would strengthen the business goals directly. Most HF Engineers focus on reducing occupational health and safety concerns (Whysall et al., 2004), but aligning HF with the strategic goals of the organisation would likely result in more successful application of HF (Dul and Neumann, 2009). The directors in this case study exhibited a strong inherent knowledge of human factors. This is in contrast to the more common belief among HF specialists that engineers and management know little about HF because they rarely realise the direct implications of poor design of equipment on operators (Perrow, 1983). However, the framing of HF by directors in this organisation focused on the importance of reducing fatigue as the human factors connection to their goal of improved quality. The mapping exercise illustrated the numerous links perceived between reduced fatigue and improved quality outcomes, such as reduced errors and earlier detection of quality problems. Fatigue was seen as both a physical risk that arises from force and repetition, which directly affects the assembly performance, and also a cognitive risk related to poor decision making and inability to detect defects and failures. While there is evidence in the HF literature for the link between HF and quality (Drury, 2000; Herrera and Huatuco, 2011; Eklund, 1995), the link between fatigue and quality is reported less often and potentially an important area of further study for improving business performance.

The discussion among the senior directors in the workshop while viewing the merged group maps emphasised their need to focus on process design and the importance of good design of equipment, layout, flow of materials, and material placement to improving quality. This 'hard systems' approach to HF in design is well documented in regards to reducing musculoskeletal disorders (Hendrick, 2008; De Looze et al., 2003), but less well documented with respect to reducing fatigue. The discussion also led to two opportunities within the organisation for furthering their strategic goals. One opportunity involved broader systems design issues, such as job enlargement and patterns of work. The second opportunity involved improving psychosocial factors such as worker motivation, involvement, and knowledge of how to do the job properly. Optimising such 'soft systems' design such as work organisation and psychosocial factors are also well-documented human factors strategies for increasing worker effectiveness (Bongers et al., 1993). The mapping therefore helped reveal their current knowledge and perceptions of socio-technical systems, but also untapped potential to further their strategic goals. It also provided the avenue to discuss their internal strengths and weaknesses, and make action plans with the potential to improve their business management practices using human factors.

\subsection{Implications for managers}

The mapping exercise revealed not only the main strategic goals of the organisation, but also how HF knowledge, expertise and action should be positioned to help achieve the strategic goals. This is of vital importance both to HF specialists and to managers, such that efforts are aligned with strategic goals, and HF will be seen to be contributing to the success of the organisation (Dul and Neumann, 2009; Drury, 2000). In this particular 
organisational context, promotion of HF for the purposes of reducing musculoskeletal injuries would have been misdirected since there are very few work-related compensation claims. However, promoting HF with a goal to reducing fatigue and improving quality became immediately apparent through this exercise. Reducing fatigue to improve performance has the added benefit of simultaneously reducing musculoskeletal injuries - regardless of whether this is an immediate goal (Ahsberg, 1998).

Organisations may benefit from having HF personnel within the Operations Management or Engineering Departments rather than separated functionally into Occupational Health and Safety Departments $(\mathrm{OH} \& \mathrm{~S})$, removed from the main production and operations. Various authors have documented the challenges facing HF specialists who are functionally located in OH\&S departments but who need to be included in engineering design. These challenges include: the different training and design process used by the two groups, the organisational positioning and rewards of engineers compared to HF specialists, the tendency of HF specialists to blame engineers for system failures, the tendency for HF to be seen as threatening, and the lack of customer demands for HF (Broberg, 2007; Kirwan, 2000; Pacquet and Lin, 2003; Perrow, 1983; Waterson and Kolose, 2010). An understanding of strategic goals and the operations links to HF can help HF specialists navigate in the engineering domain (Dul and Neumann, 2009; Theberge and Neumann, 2010). The authors believe that making this connection explicit is the first step to increasing the application of HF in the design process and developing sustainable capability in HF to improve business performance (Neumann and Village, 2012).

\subsection{Benefits of using cognitive mapping}

Cognitive mapping has been used to reveal gaps in managerial knowledge or perceptions (Fiol and Huff, 1992). Similarly, when used to map knowledge of HF, the technique may reveal people who would benefit from additional training and education about HF. The process of combining individual maps into a merged group map can be a way to encourage 'learning' about HF among senior directors in a way that 'saves face' (Eden, 1988). The visual nature of the map simplifies complex ideas and facilitates transmission between people, while divorcing any individual from specific ideas, making it less likely a participant would feel bereft or defensive regarding their concepts (Fiol and Huff, 1992). Learning takes place in the interaction of the maps and one's mental models (Moreroft, 1992). As directors compare their individual maps with the merged map, they see their ideas and concepts alongside those of their peers. Mapping causes one to self-reflect on the knowledge they possess, which produces learning and change (Nicolini, 1999). HF specialists may find that learning about HF through mapping can be more effective than other instructional techniques.

The cognitive mapping exercise successfully converted the tacit knowledge of individual directors about human factors into shared explicit knowledge in the team. There is management recognition in the literature of the importance of pulling together collective, or 'tribal' knowledge in organisations (Mohanty and Deshmukh, 1999; Savolainen, 1999), and of making the understanding explicit (Tegarden and Sheetz, 2003). Such a shared understanding about HF could enable companies to learn and develop a continuous capacity to adapt and improve (Senge, 2006). In operations research interventions, understanding the managements' perspective of the problem is vital to action and success of the interventions (Ackermann et al., 1992; Siemieniuch and 
Sinclair, 2004). With mapping, options, dilemmas and feedback loops about HF could be examined, and conflicts explored to increase understanding (Ackermann et al., 1992).

Another benefit of cognitive mapping compared to other techniques is the potential to identify emergent concepts. For example, in our case study, the concept 'reduce fatigue' mentioned by a couple individuals was linked to other concepts that were common among the group, such as 'reduce repetitive activities' and 'increase job rotation'. When the maps were merged, the concept of 'reduce fatigue' became a central concept for the group map due to the nature of merging the links in a combined map. This led to discussions and opportunities about reducing fatigue that may not have been uncovered with interviews or brainstorming, or with other traditional HF techniques (Eden and Ackermann, 2004). The technique can open the enquiry and raise further questions, as occurred during the workshop reported here. Cognitive mapping has also been highly rated for being truthful and ethical compared with a variety of methods (such as surveys, comparison matrices, soft systems methods and systems mapping). This is because participants can see what has been recorded (Brown, 1992). Especially relevant to our case study of integrating HF into design processes, cognitive mapping, compared with other techniques, is especially useful for indicating paths for action, and leading to targeted steps (Eden, 1988; Eden and Ackermann, 2004; Robertson and Williams, 2006).

Finally, the map in our example was viewed as a potential yardstick for measuring change as actions are taken and new problems are revealed - akin to a performance indicator. In this way, changes in the content and structure of the map may usefully indicate increased understanding (learning) or increased action taken to incorporate HF. Such a performance indicator may help move HF beyond health and safety to serve a deeper role in contributing to the organisational strategies.

\subsection{Suggestions when using cognitive mapping}

The open-ended question used when mapping must be carefully crafted such that sufficient and useful information can be obtained. The structure of the map depends heavily on what is asked and how the question is asked. The question should be broad such that individuals can provide details that they believe are important (Tegarden and Sheetz, 2003). Concepts must be written in a way that is action oriented or the participant should be asked to rephrase concepts. The facilitator needs the skill to keep the concepts accurate, encourage the participant to make appropriate links between concepts, and to fill in gaps or connect concepts that appear loose during the mapping process. The facilitator must therefore listen, document, link, and facilitate concurrently. While the actual mapping process is time effective (one hour), the merging of individual maps into a group map is very time consuming (approximately 20 hours in this case). The technique, therefore, would not be appropriate with large samples of individuals (Brown, 1992). Software facilitates some of the merging and analysing functions, but replaces neither careful treatment of the data, nor careful interpretation of the findings. The merging process can lead to interpretation errors or concepts that do not make sense when removed from an individual map and placed in another context. Referring back to audio recordings of the interviews, and checking information with the source can minimise these sources of error. 


\subsection{Limitations and areas for further research}

The results reported from this methodological demonstration of cognitive mapping are specific to the directors and organisation involved in this case, and cannot necessarily be generalised to other organisations or groups who may have different strategic objectives. While the sample included only seven senior directors, and cannot be assumed to represent the perceptions of the entire management team, these directors were those most responsible for design of the manufacturing production system in this case. More case study applications of cognitive mapping in different organisations are needed to refine the approach and ascertain whether the tool can consistently reveal HF knowledge or gaps in knowledge among different management groups. Communication (scholarly and otherwise) of findings about the perceived managerial links between HF and strategic goals may broaden current notions about the benefits of HF and expand learning and discussion beyond health and safety applications. Further research is needed to test whether the action items identified in the mapping exercise can translate into the anticipated benefits for strengthening business performance. Creating dynamic modelling approaches based on the relationships identified via cognitive maps are another means to further 'test' and evaluate different action options for effectiveness.

\section{Conclusions}

Cognitive mapping has been shown to be a useful tool for revealing the strategic goals of the organisation and their links to HF, and to indicate action opportunities to further strengthen this relationship. The tool allowed the tacit HF knowledge and experience of senior directors to be shared and made explicit. In this case study, directors revealed a rich understanding of HF, but not as a health and safety benefit. The directors clearly linked HF with the ability to reduce worker fatigue, which led directly and indirectly to improved assembly quality - their main strategic goal. They also identified two HF opportunities for reducing worker fatigue and improving quality - that of improved systems design, and improved psychosocial factors (such as worker motivation and involvement). Cognitive mapping has shown that HF has strong links to strategic goals in organisations, beyond health and safety benefits. Acting on these links can help companies improve human performance, and therefore business success.

\section{Acknowledgements}

The authors would like to thank the Workplace Safety and Insurance Board of Ontario and the Natural Sciences and Engineering Research Council for funding, and participants at the organisation for their time. 


\section{References}

Ackermann, F., Eden, C. and Cropper, S. (1992) 'Getting started with cognitive mapping', 7th Young OR Conference, 13-15 April 1992, University of Warwick.

Ahsberg, E. (1998:19) Perceived Fatigue Related to Work, University of Stockholm, Department of Psychology ISBN 91-7153-830-5, National Institute for Working Life, Department for Work and Health, ISBN 91-7045-485, Sweden.

Bongers, P., de Winter, C.R., Kompier, M.A.J. and Hildebrandt, V.H. (1993) 'Psychosocial factors at work and musculoskeletal disease', Scandinavian Journal of Work, Environment \& Health, Vol. 19, No. 5, pp.297-312.

Boudreau, J., Hopp, W., Mclain, J.O. and Thomas, L.J. (2003) 'On the interface between operations management and human resources management', Manufacturing and Service Operations Management, Vol. 5, No. 3, pp.179-202.

Broberg, O. (2007) 'Integrating ergonomics into engineering: empirical evidence and implications for the ergonomists', Human Factors and Ergonomics in Manufacturing, Vol. 17, No. 4, pp.353-366.

Brown, S.M. (1992) 'Cognitive mapping and repertory grids for qualitative survey research: some comparative observations', Journal of Management Studies, Vol. 19, No. 3, pp.287-307.

De Looze, M.P., Van Rhijn, J.W., Van Deursen, J., Tuinzaad, G.H. and Reijneveld, C.N. (2003) 'A participatory and integrative approach to improve productivity and ergonomics in assembly', Production Planning \& Control, Vol. 14, No. 2, pp.174-181.

Drury, C.G. (2000) 'Human factors and quality: integration and new directions', Human Factors and Ergonomics in Manufacturing, Vol. 10, No. 1, pp.45-59.

Dul, J. and Neumann, P. (2009) 'Ergonomics contributions to company strategies', Applied Ergonomics, Vol. 40, No. 4, pp.745-752.

Eden, C. (1988) 'Cognitive mapping', European Journal of Operational Research, Vol. 36, No. 1, pp.1-13.

Eden, C. and Ackermann, F. (2004) 'Cognitive mapping expert views for policy analysis in the public sector', European Journal of Operational Research, Vol. 152, No. 3, pp.615-630.

Eden, C., Ackermann, F. and Cropper, S. (1992) 'The analysis of cause maps', Journal of Management Studies, Vol. 21, No. 3, pp.309-324.

Eklund, J. (1995) 'Relationships between ergonomics and quality in assembly work', Applied Ergonomics, Vol. 26, No. 1, pp.15-20.

Eklund, J. (1997) 'Ergonomics, quality and continuous improvement - conceptual and empirical relationships in an industrial context', Ergonomics, Vol. 40, No. 10, pp.982-1001.

Fiol, C.M. and Huff, A.S. (1992) 'Maps for managers: where are we? Where do we go from here?', Journal of Management Studies, Vol. 29, No. 3, pp.267-286.

Helander, M.G. (1999) 'Seven common reasons to not implement ergonomics', International Journal of Industrial Ergonomics, Vol. 25, No. 1, pp.97-101.

Hendrick, H.W. (2008) 'Applying ergonomics to systems: some documented 'lessons learned', Applied Ergonomics, Vol. 39, No. 4, pp.418-426.

Herrera, S.H.M. and Huatuco, L.H. (2011) 'Macroergonomics intervention programs: recommendations for their design and implementation', Human Factors and Ergonomics in Manufacturing and Service Industries, Vol. 21, No. 3, pp.227-243.

Howick, S., Eden, C., Ackermann, F. and Williams, T. (2008) 'Building confidence in models for multiple audiences: the modelling cascade', European Journal of Operational Research, Vol. 186, No. 3, pp.1068-1083.

Kirwan, B. (2000) 'Soft systems, hard lessons', Applied Ergonomics, Vol. 31, No. 6, pp.663-678.

Lee, S., Courtney Jr., J.F. and O’keefe, R.M. (1992) 'A system for organizational learning using cognitive maps', Journal of Management Science, Vol. 20, No. 1, pp.23-36. 
Mohanty, R.P. and Deshmukh, S.G. (1999) 'Evaluating manufacturing strategy for a learning organization: a case', International journal of operations and production management, Vol. 19, No. 3, pp.308-387.

Moreroft, J.D.W. (1992) 'Executive knowledge, models and learning', European Journal of Operational Research, Vol. 59, No. 1, pp.9-27.

Neumann, W.P. and Dul, J. (2010) 'Human factors: spanning the gap between OM and HRM', International Journal of Operations and Production Management, Vol. 30, No. 9, pp.923-950.

Neumann, W.P. and Village, J. (2012) 'A framework supporting the process of integrating human factors into systems design', Ergonomics, Vol. 55, No. 10, pp.1140-1156.

Nicolini, D. (1999) 'Comparing methods for understanding organizational cognition', Organization Studies, Vol. 20, No. 5, pp.833-860.

Pacquet, V. and Lin, L. (2003) 'An integrated methodology for manufacturing systems design using manual and computer simulation', Human Factors and Ergonomics in Manufacturing, Vol. 13, No. 1, pp.19-40.

Perrow, C. (1983) 'The organizational context of human factors engineering', Administrative Science Quarterly, Vol. 28, No. 4, pp.521-541.

Robertson, S. and Williams, T. (2006) 'Understanding project failure: using cognitive mapping in an insurance project', Project Management Institute, Vol. 37, No. 4, pp.55-71.

Ryan, B., Qu, R., Schock, A. and Parry, T. (2011) 'Integrating human factors and operational research in a multidisciplinary investigation of road maintenance', Ergonomics, Vol. 54, No. 5, pp.436-452.

Savolainen, T.I. (1999) 'Cycles of continuous improvement. Realizing competitive advantages through quality', International Journal of Operations \& Production Management, Vol. 19, No. 11, pp.1203-1222.

Senge, P.M. (2006) The Fifth Discipline. The Art \& Practice of the Learning Organization, DoubleDay, USA.

Siemieniuch, C.E. and Sinclair, M.A. (2004) 'CLEVER: a process framework for knowledge lifecycle management', International Journal of Operations \& Production Management, Vol. 24, No. 11, pp.1104-1125.

Strauss, A. and Corbin, J. (1990) Basics of Qualitative Research. Grounded Theory Procedures and Techniques, SAGE Publications Inc., Newbury Park, California.

Tegarden, D.P. and Sheetz, S.D. (2003) 'Group cognitive mapping: a methodology and system for capturing and evaluating managerial and organizational cognition', Omega, Vol. 31, No. 1, pp.113-125.

Theberge, N. and Neumann, W.P. (2010) 'Doing 'organizational work': expanding the conception of professional practice in ergonomics', Applied Ergonomics, December, Vol. 42, No. 1, pp.76-84.

Tranfield, D. and Smith, S. (1998) 'The strategic regeneration of manufacturing by changing routines', International Journal of Operations \& Production Management, Vol. 18, No. 1, pp.114-129.

Village, J., Greig, M., Salustri, F.A. and Neumann, W.P. (2012) 'Linking human factors to corporate strategy with cognitive mapping techniques', International Ergonomics Association Triennial Conference, Recife, Brazil.

Village, J., Salustri, F. and Neumann, W.P. (2013) 'Cognitive mapping as a tool to align human factors with strategic goals in organizations', International Journal of Industrial Ergonomics, Vol. 43, No. 4, pp.304-313.

Waterson, P. and Kolose, S.L. (2010) 'Exploring the social and organizational aspects of human factors integration: a framework and a case study', Safety Science, Vol. 48, No. 4, pp.482-490.

Whysall, Z.J., Haslam, R.A. and Haslam, C. (2004) 'Processes, barriers, and outcomes described by ergonomics consultants in preventing work-related musculoskeletal disorders', Applied Ergonomics, Vol. 35, No. 4, pp.343-351. 
Wilson-Donnelly, K.A., Priest, H.A., Salas, E. and Burke, S. (2005) 'The impact of organizational practices on safety in manufacturing: a review and reappraisal', Human Factors and Ergonomics in Manufacturing, Vol. 15, No. 2, pp.135-176.

Womack, S.K., Armstrong, T.J. and Liker, J.K. (2009) 'Lean job design and musculoskeletal disorder risk: a two-plant comparison', Human Factors and Ergonomics in Manufacturing, Vol. 19, No. 4, pp.279-293.

Yin, R.K. (2009) Case Study Research Design and Methods, SAGE, Thousand Oaks, California. 